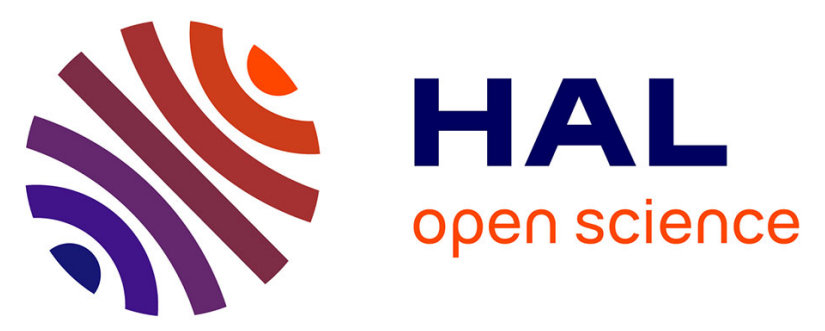

\title{
Comparative analysis of spatial genetic structure in an ant-plant symbiosis reveals a tension zone and highlights speciation processes in tropical Africa
}

Rumsais Blatrix, Jean Peccoud, Céline Born, Finn Piatscheck, Laure Benoit, Mathieu Sauve, Champlain Djieto-Lordon, Christiane Attéké, Jan Wieringa, David J Harris, et al.

\section{To cite this version:}

Rumsais Blatrix, Jean Peccoud, Céline Born, Finn Piatscheck, Laure Benoit, et al.. Comparative analysis of spatial genetic structure in an ant-plant symbiosis reveals a tension zone and highlights speciation processes in tropical Africa. Journal of Biogeography, 2017, 44 (8), pp.1856-1868. 10.1111/jbi.12972 . hal-02315946

\author{
HAL Id: hal-02315946 \\ https://hal.science/hal-02315946
}

Submitted on 14 Oct 2019

HAL is a multi-disciplinary open access archive for the deposit and dissemination of scientific research documents, whether they are published or not. The documents may come from teaching and research institutions in France or abroad, or from public or private research centers.
L'archive ouverte pluridisciplinaire HAL, est destinée au dépôt et à la diffusion de documents scientifiques de niveau recherche, publiés ou non, émanant des établissements d'enseignement et de recherche français ou étrangers, des laboratoires publics ou privés. 
1 Original article

\section{Comparative analysis of spatial genetic}

3 structure in an ant-plant symbiosis reveals a

4 tension zone and highlights speciation

${ }_{5}$ processes in tropical Africa

8 Rumsaïs Blatrix ${ }^{1}$, Jean Peccoud ${ }^{1,2}$, Céline Born ${ }^{1}$, Finn Piatscheck ${ }^{1}$, Laure Benoit ${ }^{1,3}$, Mathieu Sauve ${ }^{1}$,

9 Champlain Djiéto-Lordon ${ }^{4}$, Christiane Atteke ${ }^{5}$, Jan J. Wieringa ${ }^{6,7}$, David J. Harris ${ }^{8}$, Doyle McKey ${ }^{1,9}$

$11{ }^{1}$ CEFE UMR 5175, CNRS - Université de Montpellier - Université Paul Valéry Montpellier -

12 EPHE, 1919 route de Mende, 34293 Montpellier Cedex 5, France; ${ }^{2}$ Present address: UMR CNRS

137267 Ecologie et Biologie des Interactions, Equipe Ecologie Evolution Symbiose, Université de

14 Poitiers, Poitiers, France; ${ }^{3}$ Present address : UMR CBGP (INRA - IRD - CIRAD - Montpellier

15 SupAgro), Campus International de Baillarguet, 755 Av. du Campus Agropolis CS 30016, 34988

16 Montferrier-sur-Lez cedex, France; ${ }^{4}$ Laboratory of Zoology, University of Yaoundé 1, Yaoundé,

17 Cameroon; ${ }^{5}$ Département de Biologie, Université des Sciences et Techniques de Masuku (USTM),

18 Franceville, Gabon; ${ }^{6}$ Biosystematics Group, Wageningen Univ., Droevendaalsesteeg 1, NL-6708

19 PB Wageningen, the Netherlands; ${ }^{7}$ Naturalis Biodiversity Center, Darwinweg 2, NL-2333 CR

20 Leiden, the Netherlands; ${ }^{8}$ Royal Botanic Garden Edinburgh, 20A Inverleith Row, Edinburgh, EH3

$215 L R, U K ;{ }^{9}$ Institut Universitaire de France.

Correspondence:

24 Rumsaïs Blatrix, CEFE/CNRS, 1919 route de Mende, 34293 Montpellier cedex 5, France

25 Email: rumsais.blatrix@cefe.cnrs.fr 
27 Running title: a tension zone in central African forests

28 Word count (abstract + main text + references): 6890

\section{ABSTRACT}

\section{Aim}

33 Pleistocene climatic oscillations induced range fluctuations in African rain forest organisms and

34 may have shaped species diversification through allopatric speciation events. We compared the

35 spatial genetic structure of two forest species that live in obligate symbiosis and thus must have

36 experienced the same range fluctuations, as a means to discriminate incipient speciation from

37 transient differentiation simply resulting from past divergence.

\section{Location}

39 Western central Africa.

\section{Methods}

41 We genotyped 765 individuals of the tree Barteria fistulosa and 605 colonies of its symbiotic ant

42 Tetraponera aethiops at 12 and 13 microsatellite loci respectively. We compared the spatial genetic

43 structure of the two symbionts by using Bayesian clustering algorithms, isolation-by-distance

44 analyses and clines of synthetic alleles. We used species niche modelling (climatic and soil

45 variables) to investigate ecological variables associated with genetic discontinuities in tree 46 populations.

\section{Results}

48 The trees and the ants showed congruent patterns of spatial genetic structure. However, the trees

49 showed a very steep genetic discontinuity between groups north and south of latitude $1^{\circ} \mathrm{N}$, which

50 was much weaker in the ants. There was no evidence for effective gene flow between the two tree 
51 lineages in contact at the transition zone, despite the presence of a few hybrids. Niche modelling did

52 not predict the occurrence of northern trees south of this genetic transition, and vice versa.

\section{Main conclusions}

54 The genetic discontinuity near latitude $1^{\circ} \mathrm{N}$ is inferred to be a tension zone resulting from

55 reproductive incompatibilities between previously allopatric tree lineages. This tension zone may

56 have stabilized at a climatic transition (between boreal and austral seasonal regimes), and matches

57 patterns of genetic structure previously observed in other forest plant species. Our results illustrate

58 independent speciation between two species that live in specific and obligate symbiosis and suggest

59 that a tension zone may separate lineages of several central African forest plants near the thermal

60 equator.

\section{KEYWORDS}

62 Africa, Barteria,climatic oscillations, Guineo-Congolian rainforest, incipient speciation,

63 phylogeography, Pleistocene, symbiosis, tension zone, Tetraponera.

64 


\section{INTRODUCTION}

During the Pleistocene, Central African populations of forest-dependent species experienced

67 cycles of contraction and expansion (Maley, 1996). Because there are few mountainous areas in this

68 zone, populations of forest species had little opportunity to escape climate changes by altitudinal

69 shifts. As a consequence, the spatial extent of forest contraction/expansion cycles must have led to

70 strong population reduction and fragmentation, and species extinctions, possibly explaining the

71 lower biodiversity observed in tropical Africa than in tropical America and Southeast Asia (Morley,

72 2000). Extinctions may however be balanced by speciation events, as populations occupying

73 fragmented forest cover may evolve in isolation for considerable periods of time. This process may

74 account for several plant species radiations that were shown to have occurred during the Pliocene

75 and the Pleistocene (Harris, 2000; Wieringa \& Gervais, 2003; Plana et al., 2004; Couvreur et al., 76 2011).

The spatial genetic structure of many plant and animal species of the tropical rain forest has recently been described in the domain of Lower Guinea (i.e., western Central Africa) in order to investigate the types and locations of putative forest refugia during the Pleistocene (plants: Hardy et al., 2013; Dauby et al., 2014; Heuertz et al., 2014; Ley et al., 2014; Duminil et al., 2015; Faye,

81 2015; animals: Smith et al., 2000; Telfer et al., 2003; Bowie et al., 2006; Anthony et al., 2007;

82 Gonder et al., 2011; Nicolas et al., 2011). Notably, 10 of the 11 plant species investigated present a

83 genetic discontinuity between populations north and south of latitude $\sim 1-3^{\circ} \mathrm{N}$. A similar genetic

84 discontinuity is reported in the tree Barteria fistulosa Mast. (Passifloraceae) (Peccoud et al., 2013).

85 This recurrent genetic discontinuity is even more intriguing because the region does not show any obvious physical barrier. It is therefore tempting to assume the existence of a reproductive barrier between north and south lineages of several Central African forest plants, indicating a broad pattern of incipient allopatric speciation. However, strong genetic discontinuities not matching any obvious physical barrier within continuous species ranges may simply constitute remnants of past 
90 divergences that subsequent gene flow may erode. Addressing this uncertainty requires a detailed

91 investigation of the contact zone between genetic groups.

The tree $B$. fistulosa offers a unique opportunity to test whether the observed north-south

93 discontinuity is a sign of incipient speciation or a transient imprint of past divergence. Indeed, this

94 tree lives in obligate and specific symbiosis with the ant Tetraponera aethiops Smith, 1877

95 (Hymenoptera: Formicidae), which means that both organisms experienced the exact same range

96 fluctuations. Habitat fragmentation should therefore leave comparable genetic discontinuities

97 between the two partners. However, symbionts and hosts usually have very different life history

98 characteristics (e.g., generation time, dispersal range, mutation rate) so that their genetic structures

99 may erode at different rates (Nieberding \& Olivieri, 2007). Symbiotic partners may also differ in

100 respect to the strength of reproductive barriers that have evolved during geographical isolation, and

101 which govern the maintenance of genetic discontinuities if secondary contact occurs. As a result,

102 comparing genetic discontinuities in populations of obligate symbionts may inform on the presence

103 of such reproductive barriers and thus, on the evolutionary consequences of forest fragmentation

104 due to climatic fluctuations. This symbiosis is widely distributed in the lowlands of central Africa,

105 though restricted to the tropical rainforest, such that populations of the two species have

106 experienced fragmentation, isolation and recent expansion that are expected to have created spatial

107 genetic structure. Moreover, the two species reproduce by outcrossing, which allows interpreting

108 population genetic results in the same way for both. Finally, the association has to be re-established

109 anew at each generation, which ensures that signatures of population dynamics at neutral markers

110 are independent between the two species.

111 Here, we distinguish between reproductive isolation and transient differentiation resulting

112 simply from past divergence by confronting the spatial genetic structures of populations of the two

113 obligate symbionts, $B$. fistulosa and T. aethiops. We particularly sampled along a transect in a

114 region of supposed contact between two previously identified genetic groups of $B$. fistulosa 
115 (Peccoud et al., 2013).

\section{MATERIALS AND METHODS}

\section{Study system}

118 Barteria fistulosa trees have swollen and hollow branches presenting cavities called domatia in

119 which nests the large black ant T. aethiops. A closely related ant species, T. latifrons Emery, 1912,

120 is occasionally associated with $B$. fistulosa, although much less frequently than $T$. aethiops. The two

121 ant species can be distinguished unambiguously and T. latifrons is not considered in this paper.

122 Each tree is occupied by a single colony (Yumoto \& Maruhashi, 1999; Blatrix and Djiéto-Lordon,

123 unpublished field observations). The ant has a powerful sting and protects its host tree from

124 herbivorous insects (Janzen, 1972; Dejean et al., 2008) and vertebrates (McKey, 1974). It also

125 prunes surrounding vegetation (Janzen, 1972; Yumoto \& Maruhashi, 1999). In return, the ant

126 colony gets most of its food resources from the tree through exploitation of extrafloral nectar and of

127 hemipterans reared within domatia (Bequaert, 1922; Janzen, 1972). Fungi grown within domatia

128 constitute an additional food source for the ants (Blatrix et al., 2012).

\section{Study area and sampling}

130 Trees of B. fistulosa and associated T. aethiops ants were sampled in western Central Africa, across

131 the Lower Guinea domain (Cameroon, Gabon, Republic of Congo) (see Appendices S1 and S2 in

132 Supporting Information). Leaf samples were dried with silica gel immediately upon collection.

133 Additional samples were obtained from the National Herbarium of the Netherlands (WAG) and the

134 Royal Botanic Garden Edinburgh (E), Scotland. Samples of the symbiotic ant T. aethiops were

135 stored in $70 \%$ ethanol or dried with silica gel. Since each $B$. fistulosa tree is occupied by a single

136 colony of T. aethiops, we used only one individual ant from each tree for genetic analyses. 
138 DNA was extracted from $\sim 0.2$ g of dry leaf for each tree using the DNeasy Plant Mini Kit (Qiagen,

139 Venlo, Netherlands), and from the head of each ant with the DNeasy Tissue Kit (Qiagen), or with

140 the Extract-N-Amp PCR ReadyMix (Sigma-Aldrich, St. Louis, USA) for both ant and tree

141 specimens, following the manufacturers' instructions. Each individual of B. fistulosa was genotyped

142 for 12 microsatellite markers (Bar6, Bar16, Bar31, Bar50, Bar51, Bar53, Bar56, Bar57, Bar58,

143 Bar62, Bar64, Bar69) following a protocol described previously (Molecular Ecology Resources

144 Primer Development Consortium et al., 2012b). Each individual of T. aethiops was genotyped for

14513 microsatellite markers (Molecular Ecology Resources Primer Development Consortium et al.,

146 2012a). We used a total of 765 and 605 individuals for the tree and the ant respectively, including

147358 tree individuals that were genotyped for 11 loci by Peccoud et al. (2013).

\section{Spatial genetic structure}

149 To assess spatial genetic structure, we first used the Bayesian clustering algorithm implemented in

150 the software STRUCTURE 2.3.4 (Pritchard et al., 2000), which uses the genotypic data alone.

151 STRUCTURE was run 10 times for each number of groups assumed ( $K$ from 1 to 10$)$, considering

152 admixture and independent allele frequencies between groups (Falush et al., 2003), with the

153 admixture parameter $\alpha$ inferred from the data and given a uniform prior. Each run consisted of

1541000000 iterations, including a burn-in of 200 000. Runs for each value of $K$ were summarised

155 using CLUMPP 1.1.2 (Jakobsson \& Rosenberg, 2007). The most likely number of groups was

156 determined using the method of Evanno et al. (2005) implemented in STRUCTURE HARVESTER (Earl

157 \& vonHoldt, 2012).

158 To take spatial coordinates of sampled individuals into account, we also used the Bayesian

159 clustering algorithm implemented in the software TESS 2.3 (François et al., 2006). This approach is

160 less likely than STRUCTURE to identify genetic discontinuities that may result from uneven

161 sampling. TESS was run 10 times for each $K$ from 2 to 10, using the admixture BYM model. Each 
162 run consisted of 200000 iterations, including a burn-in of 50000 . The interaction parameter was set

163 to 0.6 . The most likely number of groups was determined by comparing the deviance information

164 criterion (DIC) among values of $K$. Congruence between the groups defined by STRUCTURE and

165 those defined by TESS was evaluated by computing the proportion of individuals that were not

166 assigned to the same group in the two analyses.

167 To assess the reality of the genetic discontinuities identified by the Bayesian clustering

168 algorithms, pairwise kinship coefficients (Loiselle et al., 1995) were computed for pairs of

169 individuals within groups, pairs among groups and all pairs. In the presence of a genetic

170 discontinuity, it is expected that kinship between individuals of different groups is lower than that

171 between individuals within the same group, for the same geographical distance. Kinship coefficients

172 were computed using SPAGEDI 1.4 (Hardy \& Vekemans, 2002) for each of 10 categories of spatial

173 distances defined so that the number of pairwise comparisons was similar across categories.

174 Jackknife standard errors were computed over loci. For each level of partition of the pairwise

175 kinship coefficients—-within groups, among groups and all pairs—we drew either a logarithmic or a

176 linear regression curve, whichever best fitted the data. Best fit was determined by comparing the

177 coefficients of determination computed by SPAGEDI. To test for spatial genetic structure, the slope

178 of the regression was tested by 9999 random permutations of locations. Pairwise $F_{\text {ST }}$ values among

179 groups were calculated with SPAGEDI using the ANOVA approach (Weir \& Cockerham, 1984).

180 We then focused on the north-south genetic discontinuity already noticed in a previous study

181 (Peccoud et al., 2013), which proved to be congruent between the ant and the tree in the present

182 study. We compared tree and ant genetic data in respect to the abruptness of the discontinuity,

183 independently of differences in allelic frequencies, by building synthetic alleles (Bierne et al., 2002)

184 and considering $K=2$ genetic groups for both species. In each species, allelic frequencies were

185 obtained from SPAGEDI for each locus and for each of the two groups. Each allele was attributed to

186 the group in which its frequency was higher, and was then replaced by this group name in the 
187 individual genotypes, creating a synthetic allele. This allowed computing the frequency of each

188 synthetic allele for each individual (averaged across loci), which we call $y$. A generalized logistic

189 function was fitted using the following formula: $y=a+(b-a) /\left(1+\mathrm{e}^{c \cdot(x-d)}\right)$, where $x$ is the individual's

190 coordinates along a transect perpendicular to the genetic discontinuity, $a$ is the low asymptote, $b$ the

191 high asymptote, $c$ the slope of the tangent at the inflexion point, and $d$ the abscissa of the inflexion

192 point. Parameters $a, b$ and $c$ describe the shape of the regression and allow comparing the

193 abruptness of the genetic discontinuity between the tree and the ant.

194 As we highlighted a particularly abrupt genetic discontinuity for the tree, we searched for

195 potential hybrids using the Bayesian method implemented in NEwHYBRIDS 1.1 (Anderson \&

196 Thompson, 2002). Individuals were assigned to one of the five following categories: each of the

197 two purebred parents, F1 and each of the two first-generation backcrosses. Uniform priors were

198 used. The Markov chain was run for 1000000 iterations, including a burn-in of 500000.

To assess whether the difference in strength of the genetic discontinuity between ants and

trees could be explained by different dispersal abilities, we compared degrees of isolation-by-

distance of the two species. To limit the influence of genetic discontinuities that may interfere with the estimate of isolation-by-distance, we restricted this analysis to within genetic groups (for two groups, including the most geographically widespread), that were congruent between the tree and the ant. For pairs of individuals of this group, average pairwise kinship coefficients (Loiselle et al., 1995) established with SPAGEDI were plotted on 10 categories of spatial distances defined so that the number of pairwise comparisons was approximately constant across categories.

\section{Species distribution modelling}

208 To explore the possibility that the main spatial genetic discontinuity in B. fistulosa could match with an environmental discontinuity (genotype-environment association), we built a species distribution model based on environmental variables for each of the two genetic groups independently and we

211 checked whether each group was predicted to occur on the opposite side of the genetic 
212 discontinuity. We used the R package 'biomod2' (Thuiller et al., 2013) with the "ensemble

213 modelling” approach. We selected seven climatic and five soil variables (see below) out of the 19

214 and seven from WorldClim (Hijmans et al., 2005) and Africa Soil Profiles Database

215 (http://www.isric.org/data/soil-property-maps-africa-1-km) respectively. Variables from the Africa

216 Soil Profiles Database contained values for six soil depths that we averaged for this study. The

217 purpose of variable selection was to remove strong correlation among variables used in the

218 modelling procedure. Among correlated variables, we selected the one that appeared the most

219 meaningful biologically according to our knowledge of the organisms. After selection, pairwise

220 correlations between variables were $<0.7$. Variables used were (names in parentheses are names of

221 the variables in their respective databases): annual mean temperature (BIO1), maximum

222 temperature of warmest month (BIO5), minimum temperature of coldest month (BIO6),

223 precipitation of wettest quarter (BIO16), precipitation of driest quarter (BIO17), precipitation of

224 warmest quarter (BIO18), precipitation of coldest quarter (BIO19), pH (PHIHO5), soil organic

225 carbon (ORCDRC), sand content (SNDPPT), silt content (SLTPPT) and bulk density (BLD). All

226 variables were used at a $10 \mathrm{~min}$. resolution. We used presence data for the focal genetic group only.

227 Presence data of the non-focal group were coded as no data, like all the cells for which we lacked

228 presence data. As there were no true absence data, five repetitions of 100 pseudo-absences were

229 generated following the Surface Range Envelope strategy. Nine different distribution models were

230 built (GLM, GBM, GAM, ANN, SRE, CTA, RF, MARS and FDA; for definition of the models see

231 reference manual of 'biomod2' at https://cran.r-project.org/web/packages/biomod2/biomod2.pdf).

232 Model evaluation was based on a five-fold cross-validation by randomly splitting the data set into

233 two subsets, one for calibrating the model (70 \% of the presence data) and one for testing the model

234 (30\% of the presence data). After removing modelling runs with an evaluation TSS score $<0.7$,

235 individual models were combined with the committee averaging algorithm (i.e., model probabilities

236 are transformed into binary data which are averaged over models). The resulting meta-model was 
237 projected on the current variables. To determine which environmental variables were most

238 important in explaining the distribution of the focal genetic group we normalized the relative

239 contributions of each variable to each run of each model and plotted the average over the 25 runs of

240 each model for each variable (five independent runs $\times$ five repetitions of generation of pseudo-

241 absences).

242 Statistical analyses and figures, unless specified otherwise, were performed using R 3.1.0 (R

243 Core Team, 2014).

\section{RESULTS}

245 Individual genotypes and collection details are presented in Appendices S1 and S2.

\section{Spatial genetic structure}

247 For the tree, DIC values obtained with TESS began to stabilize at $K=4$ groups (Appendix S3).

248 However, the $\Delta K$ value was highest for $K=2$. Thus, both values were investigated. For the ant, both

249 DIC values and $\Delta K$ indicate that the most likely number of groups is four (Appendix S3). For both

250 the tree and the ant, the genetic groups defined by TESS and STRUCTURE for $K=4$ were highly

251 congruent (only $9 \%$ and $7 \%$ of the tree and ant individuals respectively were not assigned to the

252 same group), indicating that the two algorithms gave similar results. For $K=2$, there was no

253 mismatch at all for the tree and only $0.5 \%$ of the ant individuals mismatched. We thus chose to

254 consider only the results obtained with STRUCTURE in the subsequent analyses (Fig. 1a). Kinship

255 coefficients were higher for pairwise comparisons within than among groups, whatever the

256 geographic distance (Fig. 1b), hence the genetic discontinuities are real and not the product of

257 isolation-by-distance coupled with uneven sampling. Regression of kinship coefficient on spatial

258 distance was significant for pairwise comparisons within groups, among groups and among all

259 individuals for both the ant and the tree, indicating spatial genetic structure. Kinship coefficients for

260 pairs of trees belonging to different groups (Fig. 1b, circles), and for all trees (diamonds), were 
261 better fitted by a linear than by a logarithmic regression, indicating that a process other than

262 isolation-by-distance is involved in the spatial genetic structure of B. fistulosa (Born et al., 2008).

263 This was not the case for T. aethiops.

264 In each species, the four genetic groups are spatially segregated and their distributions appear

265 congruent between the tree and the ant (Fig. 1a). However, the southernmost group of trees was

266 highly differentiated from the three other ones $\left(F_{\mathrm{ST}}=0.38\right)$, congruent with results from Peccoud et

267 al. (2013), a pattern that did not occur in the ant (Fig. 1a). In contrast, the main genetic

268 discontinuity in the ant was that between the northernmost group and the others.

\section{Characterisation of the north-south genetic discontinuity}

The frequencies of synthetic alleles representative of the northern groups (assuming $K=2$ for

271 trees and for ants) along a latitudinal transect (Fig. 2) confirm that the north-south genetic

272 discontinuity is much more abrupt in trees. Not only do asymptotes from either side of the

273 discontinuity represent more extreme (high or low) allelic frequencies in trees, but also the slope of

274 the tangent at the inflexion point is steeper for the tree (parameter $c=6.79$ ) than for the ant

$275 \quad(c=2.81)$.

276 The NEwHYBRIDS algorithm detected 21 individuals of $B$. fistulosa as potential hybrids

277 between the northern and southern groups, all of which were found within a narrow contact zone of $278 \sim 100 \mathrm{~km}$ (Fig. 3). These hybrid individuals represented $18 \%$ of the individuals sampled in this area.

279 No F1 hybrid was detected as only first-generation backcrosses were found.

\section{Isolation-by-distance within genetic groups}

281 Within two widespread genetic groups separated by the north-south genetic discontinuity, regression of pairwise kinship coefficients on spatial distance was significant both for the tree and the ant, and values were better fit by a logarithmic than a linear regression, indicating a pattern of

284 isolation-by-distance for both organisms (Fig. 1a). In the southern (blue) groups, the decline in 
285 kinship coefficients and the fit of regression are similar in ants $\left(r^{2}=0.2452\right)$ and trees $\left(r^{2}=0.2427\right)$

286 (Fig. 4a). In the northern (orange) group, the steeper decline in kinship coefficients and the better fit 287 of regression in ants $\left(r^{2}=0.0766\right)$ than in trees $\left(r^{2}=0.0018\right)$ showed that isolation-by-distance 288 within this widespread genetic group is more pronounced in ants (Fig. 4b). The same pattern was 289 observed when we considered pairs within groups for the whole sampling of trees and ants 290 (triangles in Fig. 1b).

\section{Species distribution modelling}

292 Modelling of the spatial distribution of the B. fistulosa genetic groups north and south, based on 293 environmental variables, showed similar and symmetrical genotype-environment associations for 294 the two groups, and thus, only those for the northern group are presented. The predicted distribution 295 is restricted to the northern half of Lower Guinea. The model does not predict the northern group to 296 occur where the southern group occurs (Fig. 5). Among the 12 soil and climatic variables used to 297 build the models, one had a particularly strong contribution to the explanation of the distribution of 298 the morthern genetic group: precipitation during the driest quarter (Fig. 6), which is lower in the 299 south than in the north. This was true for each of the nine modelling algorithms used in the 300 ensemble modelling procedure.

\section{DISCUSSION}

302 The tree Barteria fistulosa and its obligate ant symbiont Tetraponera aethiops both display spatial genetic structure and share the same geographic pattern of genetic discontinuities. These patterns probably result from the multiple successive events of range fragmentation through time (Maley, 1996). The Last Glacial Maximum imposed particularly dry conditions in the lowlands of tropical Africa that resulted in a considerable reduction of the forest, so that most of the surface covered by the current African rainforest has been recolonized only relatively recently (Hessler et al., 2010; 
309 gene flow has not completely erased past differentiation. Obligate symbionts are expected to show

310 spatial congruency in their genetic structures because they experienced the same range fluctuations

311 as well as a recent episode of recolonization.

312 Most values of genetic differentiation between groups are moderate, except that between the

313 southernmost tree group and the others, where differentiation reaches a value $\left(F_{\mathrm{ST}}=0.38\right)$ similar to

314 those frequently observed between plant sister species (Friar et al., 2006; Yu et al., 2013). We do

315 not consider that the southern and northern populations deserve formal description as species. We

316 rather consider they are at a stage of incipient speciation that might eventually lead to full

317 speciation. The ant does not show such a strong north-south differentiation, neither in $F_{\mathrm{ST}}$ nor in the

318 strength of shift of synthetic allele frequencies (Fig. 2). Notably, the levels of genetic differentiation

319 between the southernmost tree group and northern groups are unaffected by geographical distance

320 (Fig. 1a), indicating absence of significant gene flow across the north-south genetic discontinuity

321 since the divergence of the three northern groups. Contrariwise, the southernmost group of ants is

322 genetically closest to its parapatric group (Fig. 1a). This implies that ant genes have flowed across

323 this boundary, not that the southernmost ant population diverged more recently, since divergence

324 times must be the same as for the host trees. For parapatric ant populations to become genetically

325 closer, the duration of contact must greatly exceed the effective generation time of $B$. fistulosa ( 30

326 years), and should have left enough time for gene flow between tree groups across the north-south

327 boundary. The absence of such gene flow cannot be due to less efficient dispersal, as trees show

328 weaker within-group isolation-by-distance than ants (Fig. 4). Considering that nothing at this

329 contact zone is susceptible to impede seed or pollen dispersal, the only plausible barrier preventing

330 genes flow between $B$. fistulosa groups is reproductive isolation. Incipient allopatric speciation

331 between $B$. fistulosa group South and the other groups can explain the genetic structure of both

332 symbiotic partners, in particular the co-occurring genetic discontinuity between northern and

333 southern populations as the remnant of past allopatric divergence that gene flow has partially eroded 
334 for the ant. Comparing spatial genetic structure between species in obligatory symbiosis (Alvarez et al., 2010) thus proves useful for inferring the existence of reproductive barriers in contact zones. The north-south transition zone between Barteria fistulosa genetic groups is less than $100 \mathrm{~km}$ wide, is located near latitude $1^{\circ} \mathrm{N}$ and within this zone, approximately $20 \%$ of the individuals are of hybrid origin. Absence of effective gene flow between genetic groups despite the presence of hybrids indicates that post-zygotic isolation (hybrid unfitness) is an important component of overall reproductive isolation between these tree groups. Post-zygotic isolation can freely evolve in allopatry, under the Dobzhansky-Muller-Bateson model (Coyne \& Orr, 2004), resulting in intrinsic genetic incompatibilities that can kill or sterilize hybrids in many taxa (Presgraves, 2010). These incompatibilities generally do not result from the adaptation of populations to their respective environments, and thus cause "intrinsic" (environmentallyindependent) post-zygotic isolation (Turelli et al., 2001). Alternatively or in conjunction, hybrids may suffer from maladaptation to parental niches (ecological speciation, reviewed in Rundle \& Nosil, 2005), given that the two tree groups are predicted to populate distinct environments. Known cases of hybrid ecological maladaptation result from divergent selective pressures of considerable strength that are imposed upon parental ecotypes by plainly distinct environments, such as mountain versus plain for plants (Wang et al., 1997), limnetic versus benthic zones for sticklebacks (Rundle, 2002) or different host species for phytophagous insects (Egan \& Funk, 2009; Peccoud et al., 2014). By contrast, the predicted niches of the tree groups present subtle differences that only appeared through modelling. These differences seem to us unlikely to impose selection pressures nearly as strong as those imposed upon the aforementioned ecotypes. We therefore believe that ecology would only contribute weakly, if at all, to hybrid deficiency in B. fistulosa, especially when it is considered that the contact zone may in fact represent an intermediate environment particularly suited to hybrids (e.g., Wang et al. 1997). 
359 capacities, would mostly result from reciprocal exclusion by competition. Migrants from the other

360 side of the contact zone are outcompeted by residents, as their progeny would mostly consist of

361 deficient hybrids. The zone of contact between genetic groups can thus be seen as a "tension zone",

362 a term defining a cline maintained by a balance between dispersal and selection against hybrids

363 (Barton \& Hewitt, 1985). The spatial location of the tension zone should move freely according to

364 the relative competitive ability of each lineage at the colonization front. Modelling approaches

365 predict that the spatial location of a tension zone should stabilize on an environmental transition, a

366 phenomenon conceptualised as “the coupling hypothesis” (Bierne et al., 2011, 2013). In Barteria

367 fistulosa, edaphic and climatic conditions would sufficiently differ between the areas north and

368 south of latitude $1^{\circ} \mathrm{N}$ to explain the geographic position of the tension zone. One climatic variable

369 contributed particularly heavily to niche differentiation: precipitation during the driest quarter,

370 which was lower in the area occupied by the Southern group. It still remains to be tested whether

371 southern individuals are better adapted than northern ones to a particularly pronounced dry season.

372 Genetic differentiation between groups north and south of latitude $1-3^{\circ} \mathrm{N}$ has been detected

373 in many plant species in the Lower Guinea domain (see Introduction). Interestingly, these latitudes

374 correspond to the "climatic hinge", which is defined as the transition between the boreal and austral

375 seasonal regimes. The tension zone we revealed between Barteria fistulosa lineages in that region

376 (at $1^{\circ} \mathrm{N}$ ) suggests that other Central African forest taxa may also have undergone incipient allopatric

377 speciation during past episodes of forest fragmentation. This hypothesis, and the existence of other

378 tension zones, can be tested by genetic analyses of candidate species that occur in sufficiently high

379 densities in the equatorial region to permit adequate sampling. In combination, ecological data may

380 inform on the environmental variables_-shifts in seasonal phenology, differing soil and climate

381 conditions - that may have a stabilizing effect on secondary contact zones, and on the extent to

382 which these abiotic parameters explain the geographical genetic structure observed in several taxa

383 of the African tropical rain forest. 
To conclude, our results show that reproductive isolation can evolve independently between

obligatory symbionts, so that diversification in ant-plant symbioses does not necessarily involve cospeciation. Although this has already been inferred from the taxonomic distribution of ant-plant symbioses and phylogenetic approaches (Davidson \& McKey, 1993; Chomicki \& Renner, 2015), our study constitutes the first snapshot of ongoing disjoint speciation in these symbioses.

Surprisingly, we show that isolated populations of trees can evolve stronger reproductive isolation than their ant symbionts, even though insects have shorter generation times and generally present higher speciation rates than trees. This unexpected outcome of allopatric divergence illustrates the inherent stochasticity in the evolution of reproductive incompatibilities, which depends on the occurrence and location of mutations, so that reproductive barriers need not emerge in taxa that look more likely to speciate a priori.

In addition, our results provide insight into the process of incipient speciation after secondary contact. In central Africa, re-colonization is little constrained by landforms, allowing for more accurate perception of the effects of environmental factors other than topography on the spatial distribution of genetic discontinuities. The existence of a tension zone between lineages of Barteria fistulosa that co-localizes with an environmental transition at the climatic hinge informs us on possible ongoing speciation in other Central African forest species, and on the ecological factors that govern the location of secondary contact zones in general.

\section{ACKNOWLEDGEMENTS}

This work relied on the support of the LabEx CeMEB, Mediterranean Centre for Environment and Biodiversity, www.labex-cemeb.org. This study was funded by grants to D. M. and R. B. from the programmes of the French Agence Nationale de la Recherche "Young scientists” (research agreement no. ANR-06-JCJC-0127), “Biodiversity” (IFORA project) and “Sixth extinction” (C3A project). We are indebted to François Bretagnolle, Marie-Hélène Chevallier, Gilles Dauby, Charles 
409 Doumenge, Olivier Hardy, Judicael Mezui, Hilaire Ontsana, the National Herbarium of the

410 Netherlands and the Royal Botanic Garden Edinburgh for providing samples. We thank Marie-

411 Pierre Dubois at the "Service des Marqueurs Génétiques en Ecologie (CEFE)” and Ronan Rivallan

412 and Hélène Vignes at CIRAD Lavalette Montpellier for their help with lab work. We thank the

413 Ministry of Scientific Research and Innovation of the Republic of Cameroon, the conservator of

414 Korup National Park and the CENAREST - Gabon for permitting sample collection. We thank

415 François Rivière, Xavier Garde and the personnel of the IRD in Yaoundé for providing logistic help 416 in Cameroon.

\section{REFERENCES}

419 Alvarez, N., McKey, D., Kjellberg, F. \& Hossaert-McKey, M. (2010) Phylogeography and historical biogeography of obligate specific mutualisms. The biogeography of host-parasite interactions (ed. by S. Morand and B. Krasnov), pp. 31-39. Oxford University Press, Oxford.

Anderson, E.C. \& Thompson, E.A. (2002) A model-based method for identifying species hybrids using multilocus genetic data. Genetics, 160, 1217-1229.

Anthony, N.M., Johnson-Bawe, M., Jeffery, K., Clifford, S.L., Abernethy, K.A., Tutin, C.E., Lahm, S.A., White, L.J., Utley, J.F., Wickings, E.J. \& Bruford, M.W. (2007) The role of Pleistocene refugia and rivers in shaping gorilla genetic diversity in central Africa. Proceedings of the National Academy of Sciences USA, 104, 20432-20436.

Barton, N. H. \& Hewitt, G. M. (1985) Analysis of hybrid zones. Annual Review of Ecology and Systematics, 16, 113-148. 
433 Bierne, N., David, P., Langlade, A. \& Bonhomme, F. (2002) Can habitat specialisation maintain a mosaic hybrid zone in marine bivalves? Marine Ecology Progress Series, 245, 157-170.

435 Bierne, N., Gagnaire, P.A. \& David, P. (2013) The geography of introgression in a patchy environment and the thorn in the side of ecological speciation. Current Zoology, 59, 72-86.

Bierne, N., Welch, J., Loire, E., Bonhomme, F. \& David, P. (2011) The coupling hypothesis: why genome scans may fail to map local adaptation genes. Molecular Ecology, 20, 2044-2072.

Blatrix, R., Djiéto-Lordon, C., Mondolot, L., La Fisca, P., Voglmayr, H. \& McKey, D. (2012) Plant-ants use symbiotic fungi as a food source: new insight into the nutritional ecology of

Born, C., Kjellberg, F., Chevallier, M.-H., Vignes, H., Dikangadissi, J.-T., Sanguié, J., Wickings, E.J. \& Hossaert-McKey, M. (2008) Colonization processes and the maintenance of genetic diversity: insights from a pioneer rainforest tree, Aucoumea klaineana. Proceedings of the

Bowie, R.C., Fjeldsa, J., Hackett, S.J., Bates, J.M. \& Crowe, T.M. (2006) Coalescent models reveal the relative roles of ancestral polymorphism, vicariance, and dispersal in shaping phylogeographical structure of an African montane forest robin. Molecular Phylogenetics and Evolution, 38, 171-188.

Chomicki, G. \& Renner, S.S. (2015) Phylogenetics and molecular clocks reveal the repeated evolution of ant-plants after the late Miocene in Africa and the early Miocene in Australasia and the Neotropics. New Phytologist, 207, 411-424. 
454 Couvreur, T.L.P., Porter-Morgan, H., Wieringa, J.J. \& Chatrou, L.W. (2011) Little ecological divergence associated with speciation in two African rain forest tree genera. BMC Evolutionary Biology, 11, 296.

Coyne, J.A. \& Orr, H.A. (2004) Speciation. Sinauer Associates, Sunderland, MA.

Dauby, G., Duminil, J., Heuertz, M., Koffi, G.K., Stévart, T. \& Hardy, O.J. (2014) Congruent phylogeographical patterns of eight tree species in Atlantic Central Africa provide insights into the past dynamics of forest cover. Molecular Ecology, 23, 2299-2312.

Davidson, D.W. \& McKey, D. (1993) The evolutionary ecology of symbiotic ant-plant relationships. Journal of Hymenoptera Research, 2, 13-83.

Dejean, A., Djiéto-Lordon, C. \& Orivel, J. (2008) The plant ant Tetraponera aethiops (Pseudomyrmecinae) protects its host myrmecophyte Barteria fistulosa (Passifloraceae) through aggressiveness and predation. Biological Journal of the Linnean Society, 93, 63-69.

Duminil, J., Mona, S., Mardulyn, P., Doumenge, C., Walmacq, F., Doucet, J.L. \& Hardy, O.J. (2015) Late Pleistocene molecular dating of past population fragmentation and demographic changes in African rain forest tree species supports the forest refuge hypothesis. Journal of Biogeography, 42, 1443-1454.

Earl, D.A. \& vonHoldt, B.M. (2012) STRUCTURE HARVESTER: a website and program for visualizing STRUCTURE output and implementing the Evanno method. Conservation Genetics Resources, 4, 359-361.

Egan, S.P. \& Funk, D.J. (2009) Ecologically dependent postmating isolation between sympatric host forms of Neochlamisus bebbianae leaf beetles. Proceedings of the National Academy of Sciences of the United States of America, 106, 19426-19431. 
476 Evanno, G., Regnaut, S. \& Goudet, J. (2005) Detecting the number of clusters of individuals using the software STRUCTURE: a simulation study. Molecular Ecology, 14, 2611-2620.

478 Falush, D., Stephens, M. \& Pritchard, J.K. (2003) Inference of population structure using multilocus genotype data: linked loci and correlated allele frequencies. Genetics, 164, 1567-1587.

Faye, A. (2015) Dynamique évolutive des forêts tropicales humides d'Afrique Centrale: cas d'étude 481 de la famille des palmiers (Arecaceae). PhD Thesis. Université de Montpellier, France.

François, O., Ancelet, S. \& Guillot, G. (2006) Bayesian clustering using hidden Markov random 483 fields in spatial population genetics. Genetics, 174, 805-816.

Friar, E.A., Prince, L.M., Roalson, E.H., McGlaughlin, M.E., Cruse-Sanders, J.M., Groot, S.J.D. \& 485 Porter, J.M. (2006) Ecological speciation in the east Maui-endemic Dubautia (Asteraceae)

Gonder, M.K., Locatelli, S., Ghobrial, L., Mitchell, M.W., Kujawski, J.T., Lankester, F.J., Stewart, C.-B. \& Tishkoff, S.A. (2011) Evidence from Cameroon reveals differences in the genetic structure and histories of chimpanzee populations. Proceedings of the National Academy of Sciences of the United States of America, 108, 4766-4771.

Hardy, O.J., Born, C., Budde, K., Dainou, K., Dauby, G., Duminil, J., Ewédjé, E.E.B.K., Gomez, C., Heuertz, M., Koffi, G.K., Lowe, A.J., Micheneau, C., Ndiade-Bourobou, D., Pineiro, R. \& Poncet, V. (2013) Comparative phylogeography of African rain forest trees: a review of genetic signatures of vegetation history in the Guineo-Congolian region. Comptes Rendus Geoscience, 345, 284-296.

Hardy, O.J. \& Vekemans, X. (2002) SPAGEDI: a versatile computer program to analyse spatial genetic structure at the individual or population levels. Molecular Ecology Notes, 2, 618- 
620.

499

500

501

502

Harris, D. (2000) Rapid radiation in Aframomum (Zingiberaceae): evidence from nuclear ribosomal DNA internal transcribed spacer (ITS) sequences. Edinburgh Journal of Botany, 57, 377395.

Hessler, I., Dupont, L., Bonnefille, R., Behling, H., Gonzalez, C., Helmens, K.F., Hooghiemstra, H., Lebamba, J., Ledru, M.P., Lezine, A.M., Maley, J., Marret, F. \& Vincens, A. (2010) Millennial-scale changes in vegetation records from tropical Africa and South America during the last glacial. Quaternary Science Reviews, 29, 2882-2899.

Heuertz, M., Duminil, J., Dauby, G., Savolainen, V. \& Hardy, O.J. (2014) Comparative phylogeography in rainforest trees from Lower Guinea, Africa. Plos One, 9, e84307.

Hijmans, R.H., Cameron, S.E., Parra, J.L., Jones, P.G. \& Jarvis, A. (2005) Very high resolution interpolated climate surfaces for global land areas. International Journal of Climatology, 25, 1965-1978.

Jakobsson, M. \& Rosenberg, N.A. (2007) CLUMPP: a cluster matching and permutation program for dealing with label switching and multimodality in analysis of population structure. Bioinformatics, 23, 1801-1806.

Janzen, D.H. (1972) Protection of Barteria (Passifloraceae) by Pachysima ants (Pseudomyrmecinae) in a Nigerian rain-forest. Ecology, 53, 885-892.

Ley, A.C., Dauby, G., Köhler, J., Wypior, C., Röser, M. \& Hardy, O.J. (2014) Comparative phylogeography of eight herbs and lianas (Marantaceae) in central African rainforests. Frontiers in Genetics, 5, 403.

519 Lezine, A.M., Assi-Kaudjhis, C., Roche, E., Vincens, A. \& Achoundong, G. (2013) Towards an 

understanding of West African montane forest response to climate change. Journal of Biogeography, 40, 183-196.

Loiselle, B.A., Sork, V.L., Nason, J. \& Graham, C. (1995) Spatial genetic structure of a tropical understory shrub, Psychotria officinalis (Rubiaceae). American Journal of Botany, 82, $1420-1425$.

Maley, J. (1996) The African rain forest - main characteristics of changes in vegetation and climate from the Upper Cretaceous to the Quaternary. Proceedings of the Royal Society of Edinburgh. Section B: Biology, 104, 31-73.

McKey, D. (1974) Ant-plants: selective eating of an unoccupied Barteria by a Colobus monkey. Biotropica, 6, 269-270.

Molecular Ecology Resources Primer Development Consortium, A'Hara, S.W., Amouroux, P., et al. (2012a) Permanent genetic resources added to Molecular Ecology Resources Database 1 August 2011-30 September 2011. Molecular Ecology Resources, 12, 185-9.

Molecular Ecology Resources Primer Development Consortium, Arias, M.C., Arnoux, E., et al. (2012b) Permanent genetic resources added to Molecular Ecology Resources Database 1 December 2011-31 January 2012. Molecular Ecology Resources, 12, 570-2.

Morley, E.J. (2000) Origin and evolution of tropical rain forest. Wiley, Chichester, United Kingdom.

541 Nieberding, C. M. \& Olivieri, I. (2007) Parasites: proxies for host genealogy and ecology? Trends 
in Ecology \& Evolution, 22, 156-165.

543 Peccoud, J., de la Huerta, M., Bonhomme, J., Laurence, C., Outreman, Y., Smadja, C.M. \& Simon, J.-C. (2014) Widespread host-dependent hybrid unfitness in the pea aphid species complex.

Peccoud, J., Piatscheck, F., Yockteng, R., Garcia, M., Sauve, M., Djiéto-Lordon, C., Harris, D.J., Evolution, 68, 2983-2995. Wieringa, J.J., Breteler, F.J., Born, C., McKey, D. \& Blatrix, R. (2013) Multi-locus phylogenies of the genus Barteria (Passifloraceae) portray complex patterns in the evolution

Presgraves, D.C. (2010) The molecular evolutionary basis of species formation. Nature Reviews Pleistocene Begonia speciation in Africa. Molecular Phylogenetics and Evolution, 31, 449-

Pritchard, J.K., Stephens, M. \& Donnelly, P. (2000) Inference of population structure using Genetics, 11, 175-180.

R Core Team (2014) R: A language and environment for statistical computing. R Foundation for multilocus genotype data. Genetics, 155, 945-959.

Rundle, H.D. (2002) A test of ecologically dependent postmating isolation between sympatric sticklebacks. Evolution, 56, 322-329.

Rundle, H.D. \& Nosil, P. (2005) Ecological speciation. Ecology Letters, 8, 336-352. 

conservation. Molecular Ecology, 9, 1505-1516.

Telfer, P.T., Souquiere, S., Clifford, S.L., Abernethy, K.A., Bruford, M.W., Disotell, T.R., Sterner, K.N., Roques, P., Marx, P.A. \& Wickings, E.J. (2003) Molecular evidence for deep phylogenetic divergence in Mandrillus sphinx. Molecular Ecology, 12, 2019-2024.

Thuiller, W., Georges, D. \& Engler, R. (2013) Biomod2: Ensemble platform for species distribution modeling. R package version 3.1-18. http://CRAN.Rproject.org/package=biomod2

Turelli, M., Barton, N.H. \& Coyne, J.A. (2001) Theory and speciation. Trends in Ecology \& Evolution, 16, 330-343.

Wang, H., McArthur, E.D., Sanderson, S.C., Graham, J.H. \& Freeman, D.C. (1997) Narrow hybrid zone between two subspecies of big sagebrush (Artemisia tridentata: Asteraceae). IV. Reciprocal transplant experiments. Evolution, 51, 95-102.

Weir, B.S. \& Cockerham, C.C. (1984) Estimating F statistics for the analysis of population structure. Evolution, 38, 1358-1370.

Wieringa, J.J. \& Gervais, G.F. (2003) Phylogenetic analyses of combined morphological and molecular data sets on the Aphanocalyx-Bikinia-Tetraberlinia group (Leguminosae, Caesalpinioideae, Detarieae s.l.). Advances in legume systematics, part 10, Higher level systematics (ed. by B.B. Klitgaard and A. Bruneau), pp. 181-196. Royal Botanic Garden, Kew, UK.

Yu, Q., Wang, Q., Wu, G., Ma, Y., He, X., Wang, X., Xie, P., Hu, L. \& Liu, J. (2013) Genetic differentiation and delimitation of Pugionium dolabratum and Pugionium cornutum (Brassicaceae). Plant Systematics and Evolution, 299, 1355-1365. 
(Pachysima) aethiops (Pseudomyrmecinae, Hymenoptera) in Barteria fistulosa in a tropical forest, Democratic Republic of Congo. Ecological Research, 14, 393-404.

Additional Supporting Information may be found in the online version of this article:

591 Appendix S1 List of Barteria fistulosa samples and data.

592 Appendix S2 List of Tetraponera aethiops samples and data.

593 Appendix S3 Selection of the number of genetic groups.

\section{BIOSKETCHES}

596 Rumsaïs Blatrix and the team at CEFE are interested in the functional ecology and evolutionary 597 biology of species interactions, with a particular emphasis on ant-plant symbioses.

598 Author contributions: D.M. and R.B. conceived the ideas; R.B., D.M., C.B., C.D.-L., C.A., D.J.H. 599 and J.J.W. contributed to field work; J.P., C.B., F.P., L.B., M.S., C.D.-L. and R.B. performed lab 600 work and analysed molecular data; R.B., D.M., J.P., C.B., F.P., J.J.W. and D.J.H. interpreted the 601 results; and R.B., J.P. and D.M. wrote the paper. All co-authors revised and approved the 602 manuscript.

603

604 Editor: Richard Ladle 
FIGURE LEGENDS:

607 Figure 1: (a) Spatial distribution of the genetic groups defined by STRUCTURE for $K=4$, for the tree

608 Barteria fistulosa and its symbiotic ant Tetraponera aethiops. Each individual is represented by a

609 pie chart indicating the proportions of ancestry to each of the four groups. Groups are coded by

610 colour. Pie charts are slightly shifted from true location to reduce overlap. The map was generated

611 using QGIS 2.8.1 with a Mercator projection. (b) Average kinship coefficient as a function of spatial

612 distance for all pairs of individuals (black diamond), for pairs of individuals within genetic groups

613 (triangles) and for pairs of individuals among groups (circles). Genetic groups $(K=4)$ were defined

614 using the software STRUCTURE. Dotted lines represent regression curves, either linear or logarithmic

615 according to the best fit.

616 Figure 2: Variation of the frequency of the synthetic allele $n$ (representative of the Northern group)

617 with latitude when considering the two genetic groups defined by STRUCTURE. A generalized

618 logistic function is fitted on the scatter-plot, the equation of which is given for each species.

619 Figure 3: Spatial distribution of the genetic groups of the tree Barteria fistulosa defined by

620 STRUCTURE for $K=2$. Potential hybrids between the two groups were identified using

621 NEwHYBRIDS. The right panel shows a close-up of the rectangle, where all potential hybrids occur.

622 The map was generated using QGIS 2.8.1 with a Mercator projection.

623 Figure 4: Average pairwise kinship coefficient as a function of geographical distance for pairs of

624 individuals of the ant Tetraponera aethiops (empty circles) and of the tree Barteria fistulosa (filled

625 circles) within two genetic groups defined by STRUCTURE: (a) the southernmost group, coloured in

626 blue in Fig. 1a, and (b) the most widespread of the northern groups, coloured in orange in Fig. 1a.

627 Figure 5: Projection of the consensus model (committee averaging over nine modelling algorithms)

628 of spatial distribution of the Barteria fistulosa genetic group north. Points represent all the Barteria

629 fistulosa individuals sampled. Individuals classified in group north by STRUCTURE for $K=2$ were

630 used as presence data for building the distribution model. Distribution of group south was also 
631 modelled and results for both groups were similar and symmetrical. Thus, only those for group

632 north are presented. The map was generated using QGIS 2.8.1 with a Mercator projection.

633 Figure 6: Normalized relative contributions of each of 12 environmental variables to nine different

634 models of species distribution run for the northern genetic group of the tree Barteria fistulosa

635 defined by STRUCTURE for $K=2$. Variables are: sand content (SNDPPT), silt content (SLTPPT), pH

636 (PHIHO5), soil organic carbon (ORCDRC), and bulk density (BLD), annual mean temperature

637 (BIO1), maximum temperature of warmest month (BIO5), minimum temperature of coldest month

638 (BIO6), precipitation of wettest quarter (BIO16), precipitation of driest quarter (BIO17),

639 precipitation of warmest quarter (BIO18) and precipitation of coldest quarter (BIO19).

640 
641 Figure 1

(a) Barteria fistulosa

Tetraponera aethiops

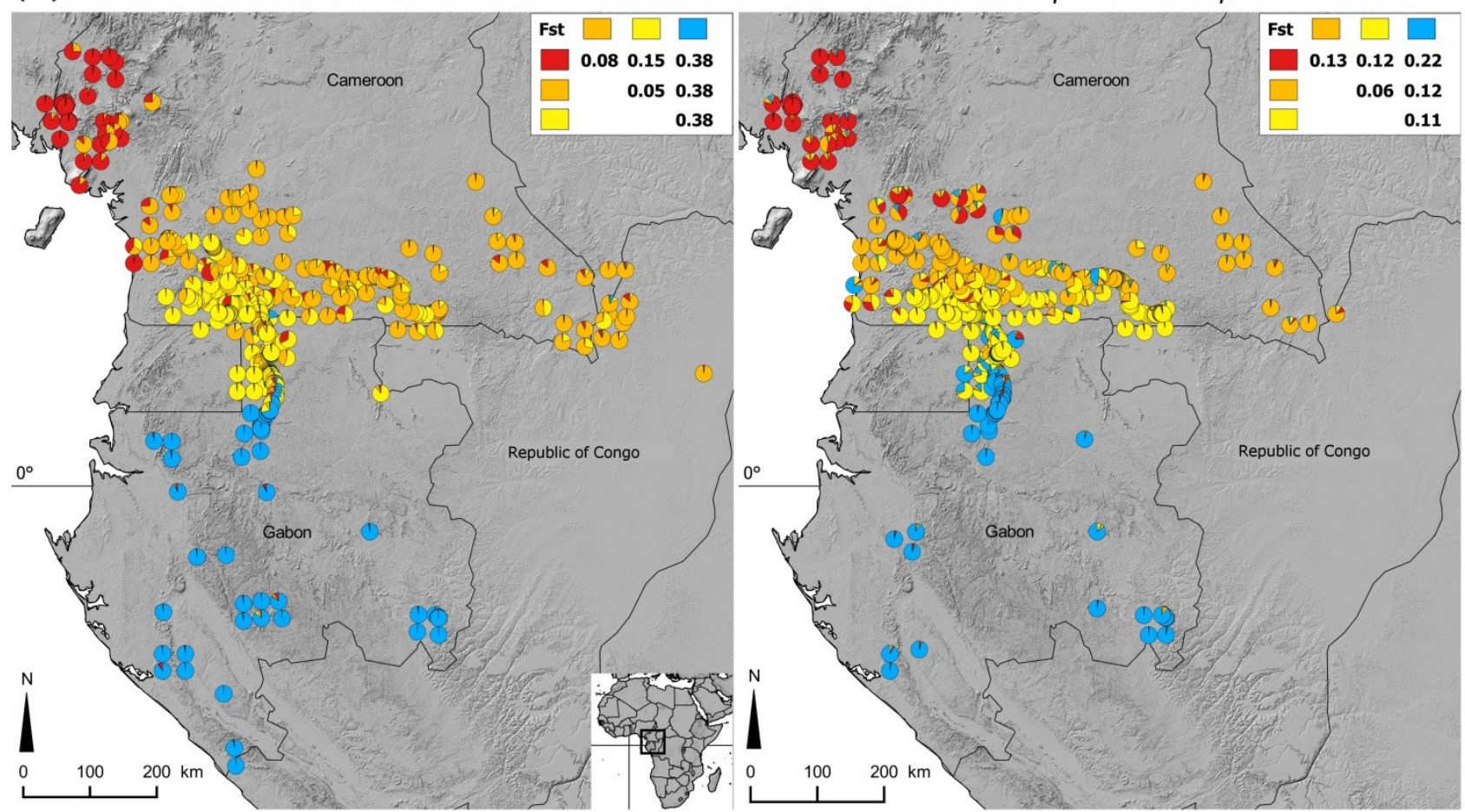

(b)

Barteria fistulosa

Tetraponera aethiops
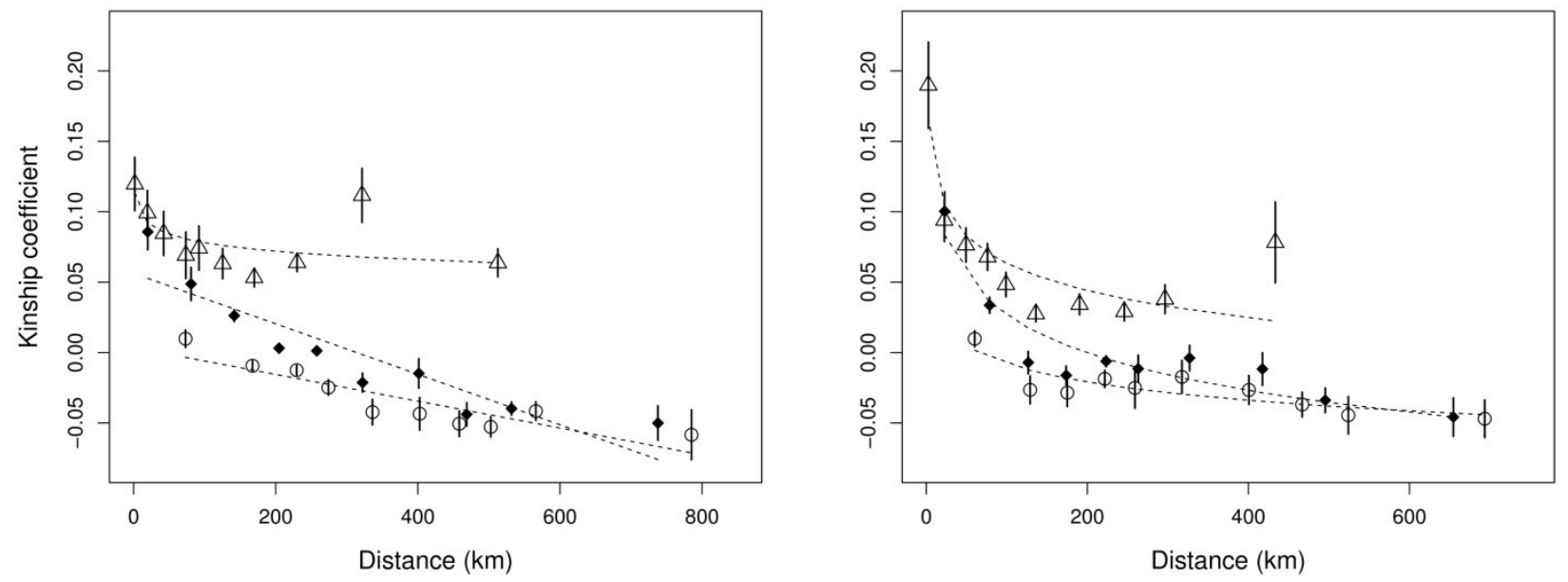

642

643 


\section{Figure 2}

\section{Barteria fistulosa}

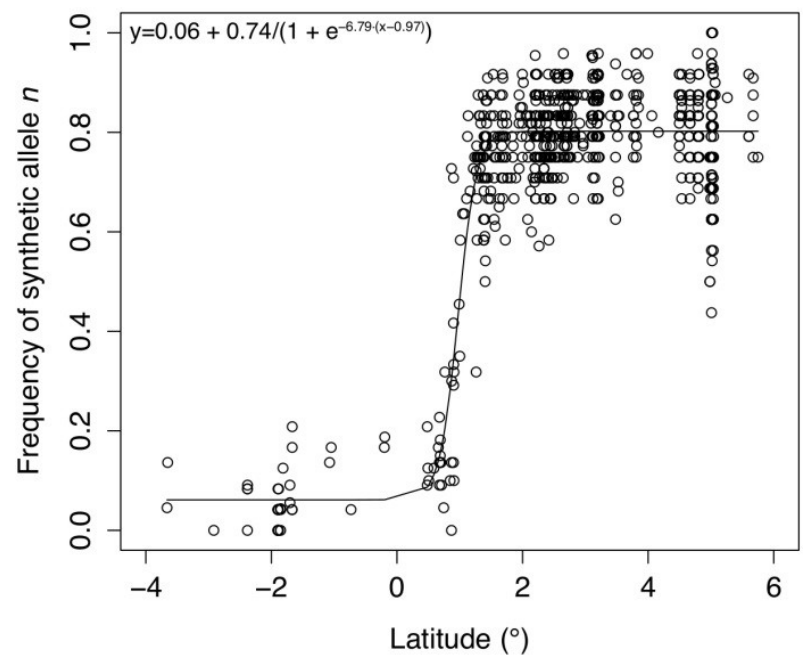

Tetraponera aethiops

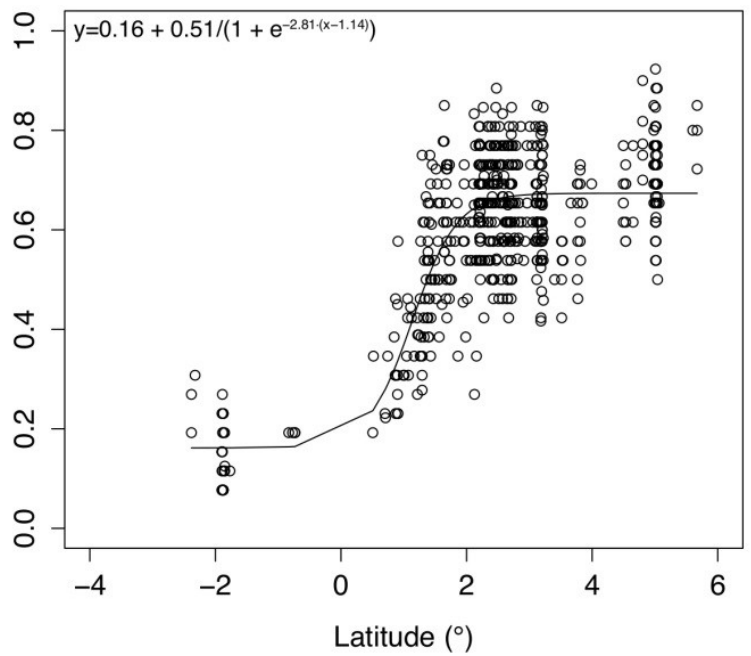

645

646 
647 Figure 3

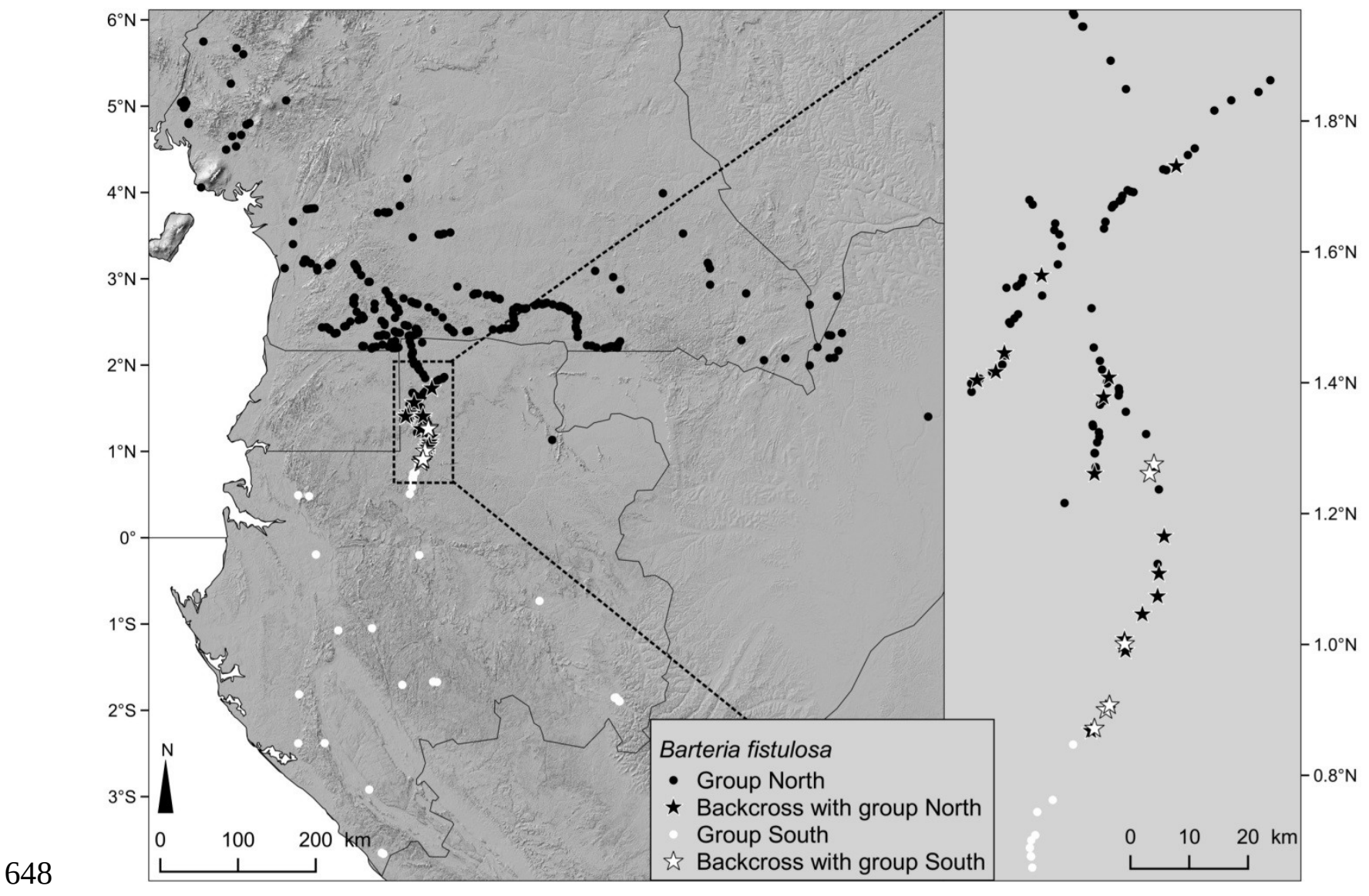


$650 \quad$ Figure 4

(a)

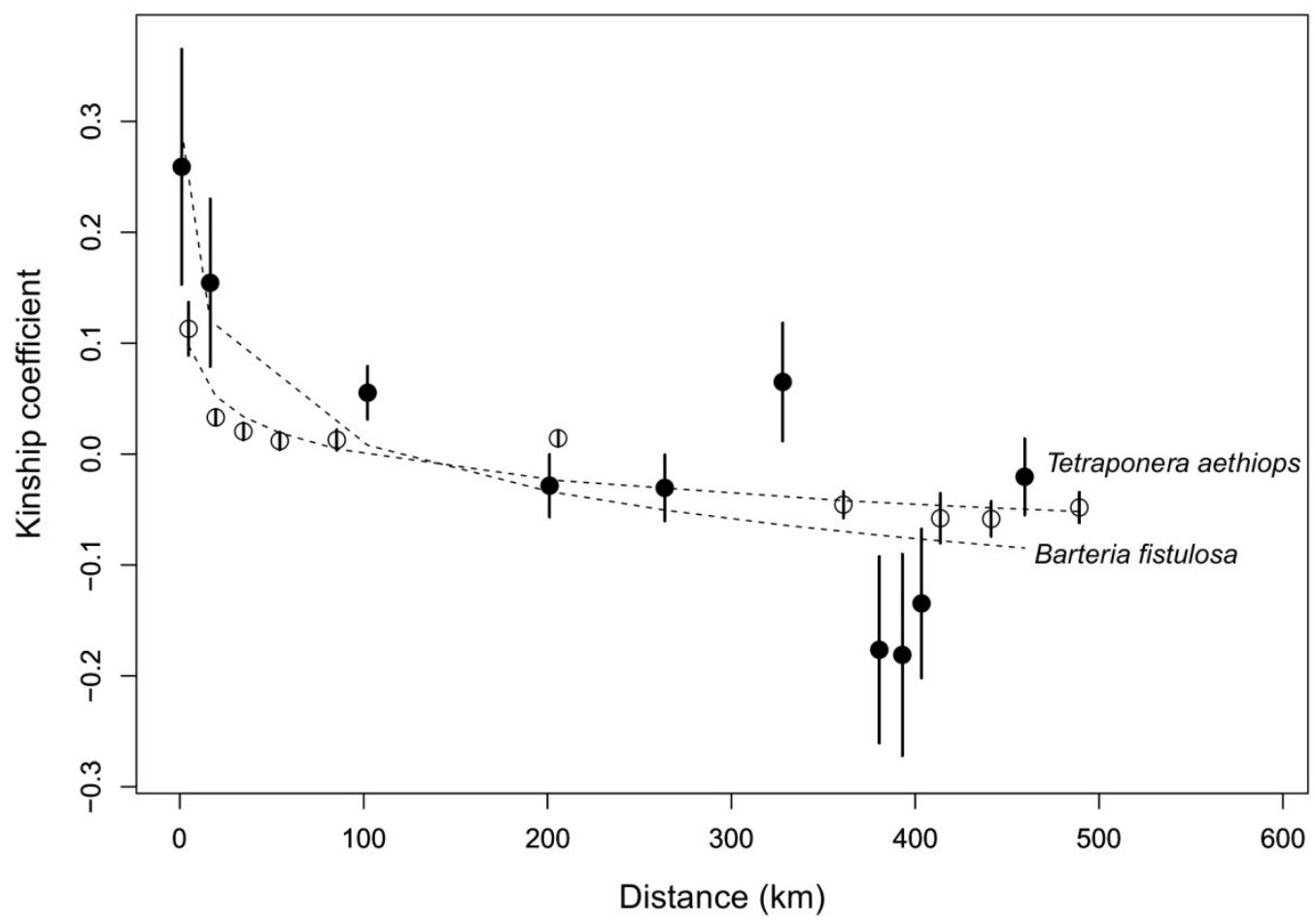

(b)

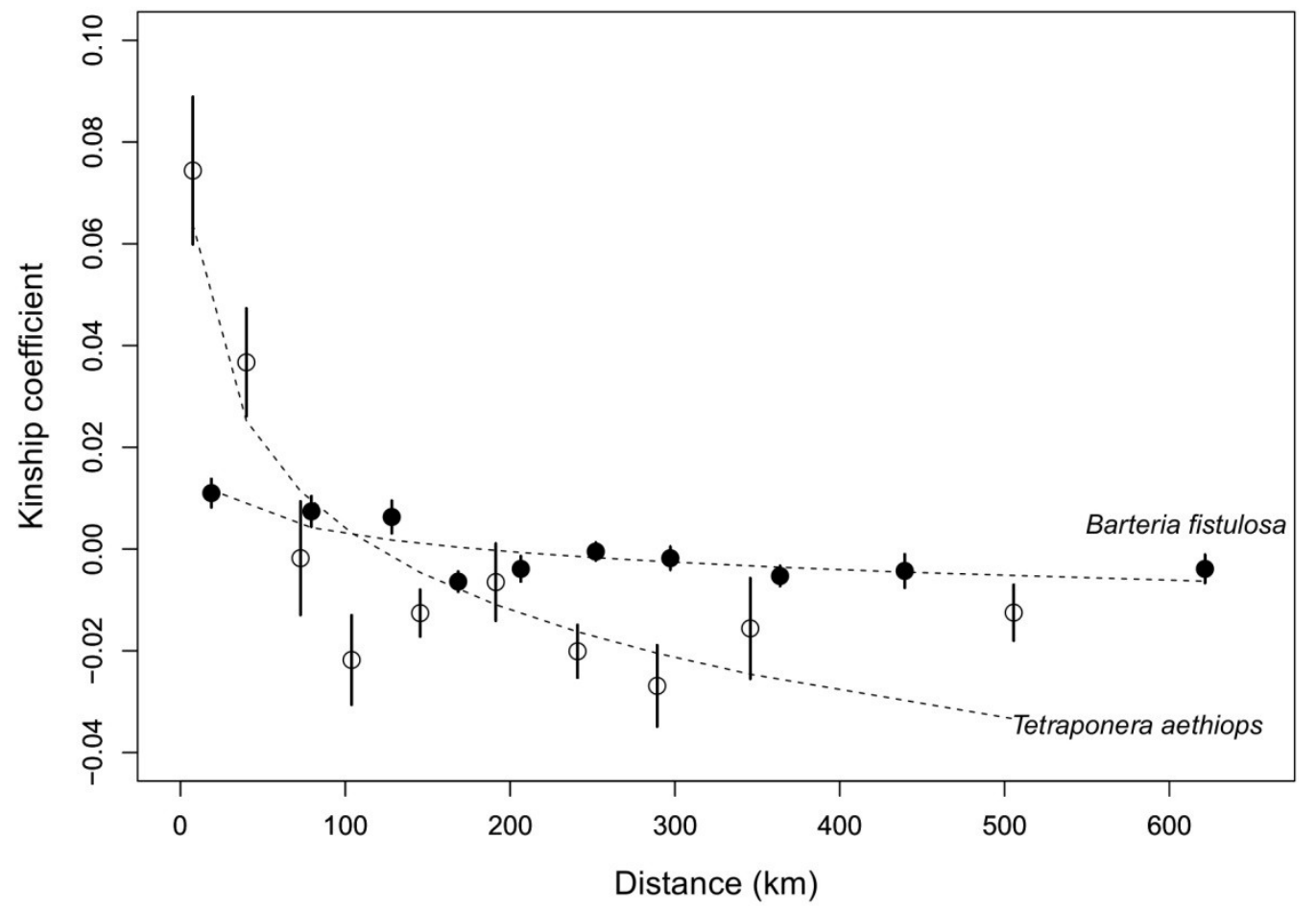


653 Figure 5

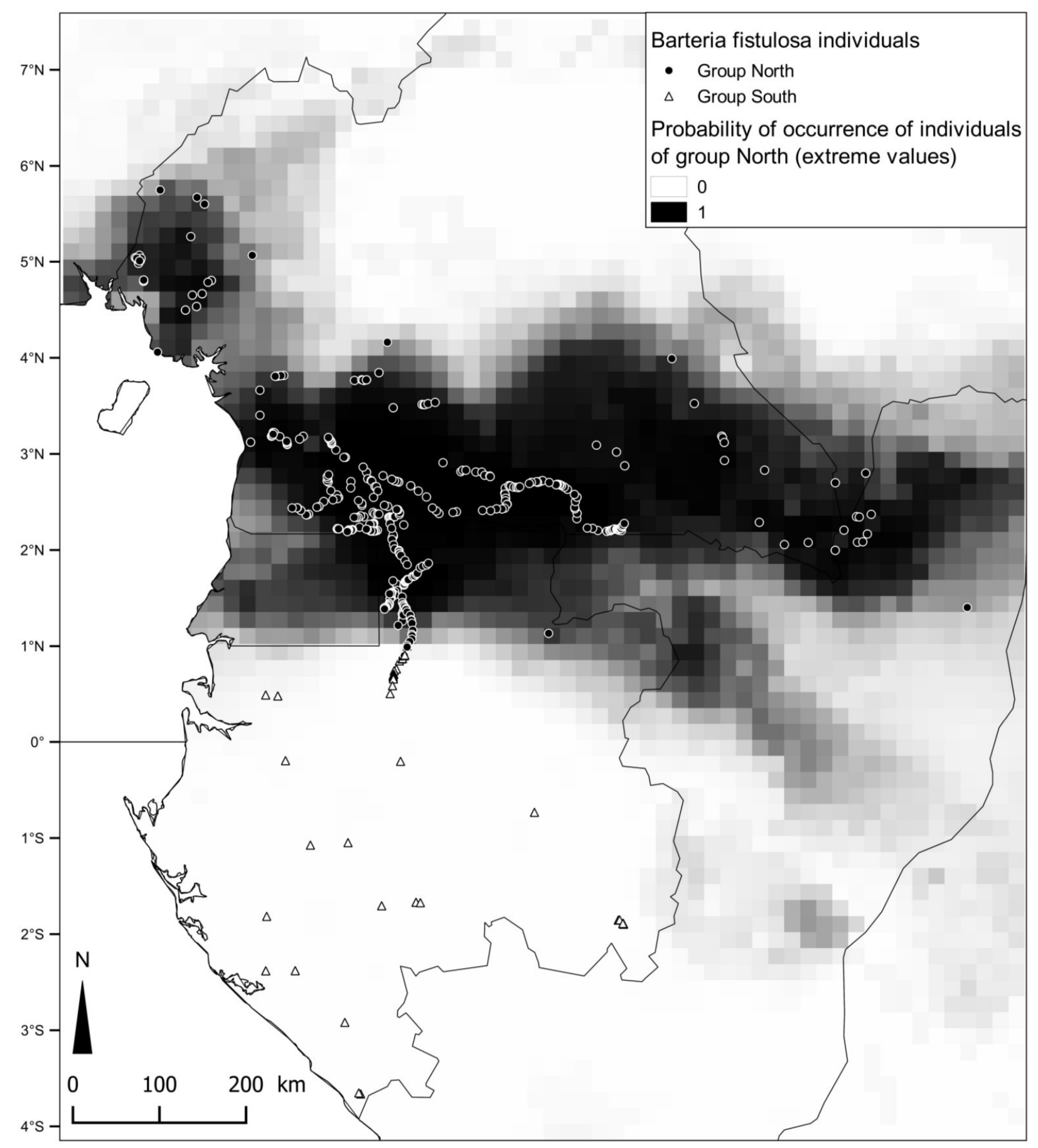

654

655 


\section{Figure 6}

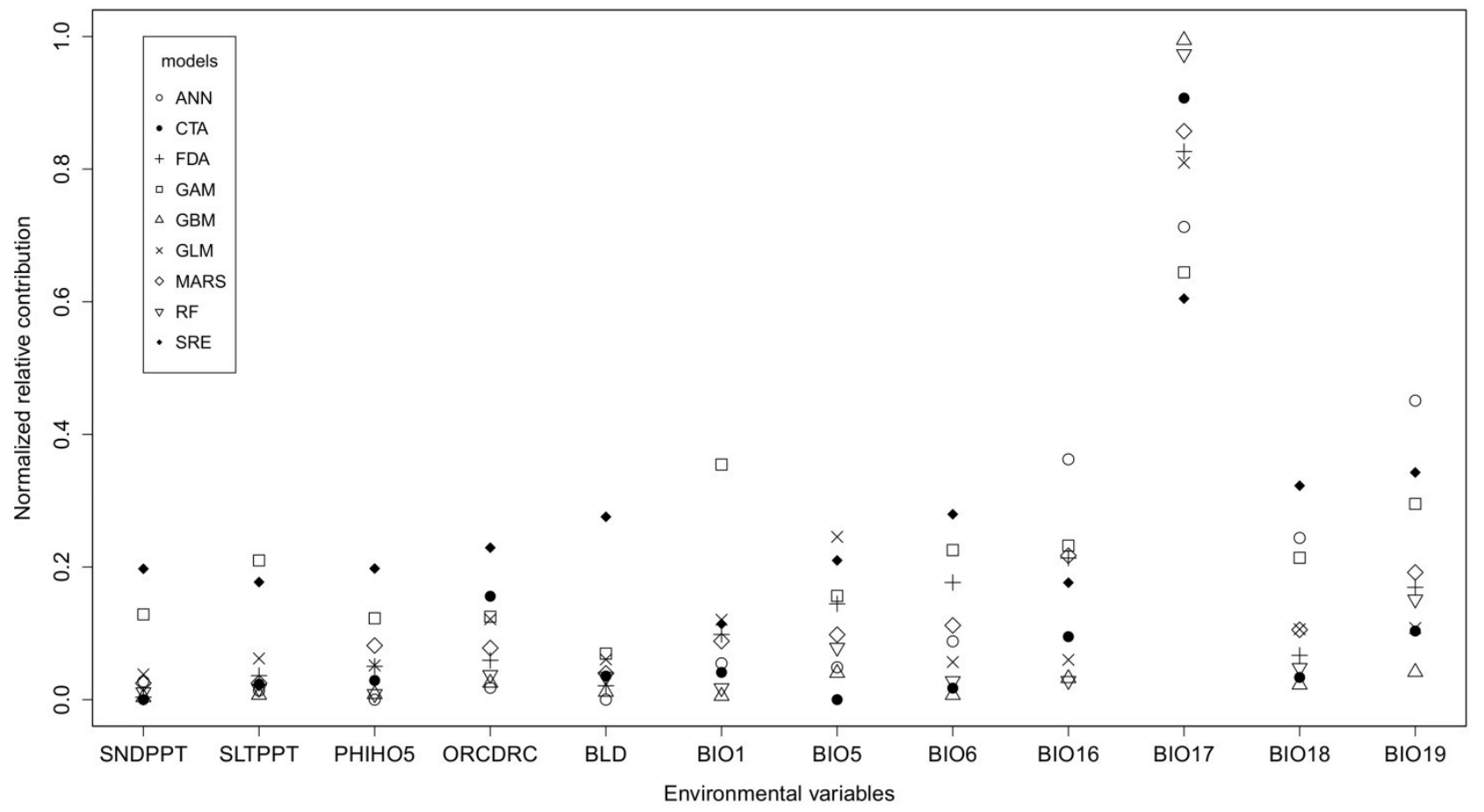

